DOI 10.15593/2224-9354/2017.3.23

УДК 553.9.08

У.В. Афтахова, Н.Ю. Старкова

\author{
ФОРМИРОВАНИЕ МЕТОДИКИ ОЦЕНКИ УРОВНЯ \\ ПОТЕНЦИАЛЬНЫХ ЗАПАСОВ УГЛЕВОДОРОДОВ \\ НА МЕСТОРОЖДЕНИИ НА ОСНОВЕ СТОХАСТИЧЕСКОГО \\ МОДЕЛИРОВАНИЯ
}

\begin{abstract}
Обосновывается необходимость оценки уровня потенциальных запасов углеводородов на месторождении. Анализ специализированной литературы позволил сделать вывод о том, что при принятии решения об инвестировании средств в проект разработки месторождения особое внимание уделяется показателю уровня прогнозных ресурсов нефти. По мнению авторов, проблема неточности оценки запасов крайне актуальна сегодня, так как потенциальная некорректность при прогнозировании объема углеводородного сырья может привести к недополучению экономического эффекта при разработке месторождения. В качестве наиболее приемлемого подхода к определению уровня достоверности оценки запасов в условиях рисков было принято стохастическое моделирование на основе метода Монте-Карло. По мнению авторов, применение данного математического инструментария позволит наиболее точно определить подсчетные параметры месторождения. Предлагаемая методика апробирована на примере Речного месторождения, принадлежащего ООО «ЛУКОЙЛ-Пермь». По данным предприятия нефтеносность месторождения составляет 215 тыс. т. Расчеты по методике, предлагаемой авторами, показали, что предполагаемые объемы полезных ископаемых превышены, что, безусловно, приведет к снижению эфффективности проекта разработки месторождения. Представлены расчеты экономической эффективности инвестиций в проект разработки Речного месторождения. Сравнение показателей эффрективности проекта с применением авторской методики и без нее показало, что более детальная оценка уровня потенциальных запасов Речного месторождения позволит повысить рентабельность проекта.

Ключевые слова: нефртегазовые компании, определение уровня достоверности оценки запасов, прогноз нефртеносности, метод Монте-Карло, экономический эфрфект.
\end{abstract}

Реализация мероприятий на поисково-оценочном этапе геолого-разведочных работ, как и дальнейшее функционирование и развитие нефтегазового предприятия, предполагает наличие капитальных вложений, которые, как известно, всегда сопровождаются определенными рисками, объективно обусловленными самим фактом реализации предпринимательской деятельности. Риск представляет собой сложную экономико-управленческую категорию, при определении которой имеет место множество противоречивых ха-

(C) Асртахова У.В., Старкова Н.Ю., 2017

Афтахова Ульяна Владимировна - ст. преподаватель кафедры экономики и управления промышленным производством ФГБОУ ВО «Пермский национальный исследовательский политехнический университет», e-mail: ulianaaft@ yandex.ru.

Старкова Нелли Юрьевна - магистрант кафедры экономики и управления промышленным производством ФГБОУ ВО «Пермский национальный исследовательский политехнический университет», e-mail: nelly9418@ mail.ru. 
рактеристик. Наиболее распространенные из них - это угроза или опасность возникновения ущерба, потерь ресурсов или вероятность прекращения ведения хозяйственной деятельности. Глубина анализа степени рискованности действий бизнеса зависит от конкретного плана деятельности и масштаба проекта. Для крупных проектов необходим тщательный просчет рисков с использованием серьезного математического аппарата. Для более простых проектов достаточен анализ риска с помощью метода экспертных оценок [1].

Среди всех рисков, влияющих на деятельность нефтегазового предприятия, необходимо особо выделить наличие вероятности ошибки при расчете прогнозных ресурсов нефти [2, 3]. Показатель уровня прогнозных ресурсов нефти играет ключевую роль при оценке целесообразности реализации инвестиционного проекта по добыче углеводородов, так как неточность оценки запасов влечет завышение или занижение экономического эффекта, что, безусловно, приведет к различного рода потерям и недооценке производственных мощностей, обусловливая полную или частичную замену оборудования или даже смену модели обустройства месторождения в целом [4]. В этой связи принятый проект может оказаться неэффективным для инвестирования, и предприятие понесет значительные убытки.

Анализируя причины возникновения ошибок при оценке запасов месторождения, необходимо выделить следующие [5, 6]:

1) неточность картирования структуры на этапе исследования, что дает ошибку при проектировании заложения скважины - риск попадания в плотные породы ненасыщенные нефтью;

2) погрешность в проведении и/или интерпретации данных;

3) отсутствие значений подсчетных параметров, принятых при проведении лабораторных исследований, и приравнивание их к месторождениюаналогу [7].

Чем реалистичнее представлены вышеописанные данные, тем более точным будет значение количественной оценки ресурсов, что дает основание считать предполагаемый экономический эффект наиболее близким к достоверному.

В качестве наиболее приемлемого подхода определения уровня достоверности оценки запасов в условиях рисков было принято стохастическое моделирование на основе метода Монте-Карло. Суть вероятностного подхода заключается в том, что все исходные параметры выражены диапазоном возможных значений от минимально до максимально возможного, с акцентированием на наиболее вероятное; диапазон значений выражен в виде распределения в пределах одного нефтегазоносного комплекса. Распределения параметров приняты на основании анализа статистических данных по месторождениям-аналогам [8, 9]. 
Для объекта выделены три основных уровня оценки:

1) наименьшая оценка (вероятность P90) - 90\%-я уверенность в том, что будет получен данный объем нефти;

2) наибольшая оценка (вероятность $P 10)$ - 10\%-я уверенность в том, что будет получен данный объем нефти;

3) наиболее достоверная оценка (вероятность Pmean) - соответствует среднему значению диапазона возможных объемов ресурсов.

Данная вероятность рассчитывается на основе интегрирования функции [6]:

$$
P=1-\int f(x),
$$

где $P$ - вероятность; $f(x)$ - значения функции распределения.

Формализация данного инструментария осуществляется в виде постановки многокритериальной задачи, алгоритм решения которого представлен на рис. 1.

Шаг 1. Анализ статистических данных подсчетных параметров по месторождениям-аналогам

\begin{tabular}{|c|c|}
\hline$\downarrow$ & 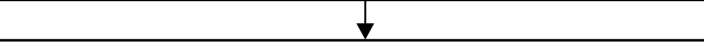 \\
\hline $\begin{array}{l}\text { Шаг 2. Формирование гистограмм } \\
\text { распределения параметров }\end{array}$ & $\begin{array}{l}\qquad P=1-\int f(x), \\
\text { где } P \text { - вероятность. } \\
P 90-90 \% \text {-я уверенность в том, что будет получен } \\
\text { данный объем нефти; }\end{array}$ \\
\hline$\downarrow$ & $\begin{array}{l}P 10 \text { - 10\%-я уверенность в том, что будет получен } \\
\text { данный объем нефти: }\end{array}$ \\
\hline Шаг 3. Проверка типа & Pmean - соответствует среднему значению \\
\hline распределения по критерию & $\frac{1}{7}$ \\
\hline КОлМОіорова-С - мирнова & $D_{m \cdot n}=\sup \left|F_{m}(x)-G_{n}(x)\right|$, \\
\hline$\nabla$ & $D$ - степень различия между распределениями $m$ и $n$; \\
\hline $\begin{array}{l}\text { Шаг 4. Выявление параметров, } \\
\text { согласно типу распределения }\end{array}$ & $\begin{array}{l}x \text { - разряды, По которым рассчитываются разницы; } \\
F_{m} \text { - частотное распределение } m ; G_{n}-\text { частотное } \\
\text { распределение } n\end{array}$ \\
\hline$\downarrow$ & $\nabla$ \\
\hline $\begin{array}{l}\text { Шаг 5. Проведение итераций для } \\
\text { определения уровней оценки }(P 10, \\
P \text { mean, } P 90) \text { извлекаемых запасов } \\
\text { нефти }\end{array}$ & $\begin{array}{c}N P V=-I C+\sum_{1}^{n} D C F \\
\sum_{1}^{n} D C F\end{array}$ \\
\hline$\downarrow$ & \\
\hline Шаг 6. Оценка экономической & $D P P=\frac{I C}{\sum D C F}$ \\
\hline $\begin{array}{l}\text { ЭФФективности инвестиционного } \\
\text { проекта [11] }\end{array}$ & $I R R=E+\frac{N P V}{N P V-\left(N P V^{\prime}\right)} *\left(E^{\prime}-E\right)$ \\
\hline
\end{tabular}

Рис. 1. Пошаговое обоснование необходимости реализации метода Монте-Карло при оценке экономической эффективности инвестиционного проекта 
В основу выполненной вероятностной оценки положена формула объемного метода подсчета запасов [10]:

$$
Q_{\text {извл }}=F \cdot h_{\text {эф.н }} \cdot k_{\text {пор }} \cdot k_{\mathrm{H}} \cdot \rho_{\mathrm{H}} \cdot \theta \cdot \mathrm{KИН,}
$$

где $Q_{\text {извл }}$ - извлекаемые запасы нефти, тыс. т; $F$ - площадь нефтеносности, км $^{2} ; h_{\text {эф.н }}$ - эффективная нефтенасыщенная толщина, м; $k_{\text {пор }}-$ коэффициент пористости, д. ед.; $k_{\text {н }}-$ коэффициент нефтенасыщенности, д.ед.; $\rho_{\text {н }}-$ плот-

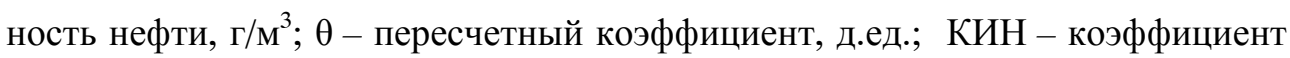
извлечения нефти, д.ед.

Апробация инструмента оценки уровня достоверности ресурсов нефти, а следовательно, и экономического эффекта была проведена на примере Речного месторождения нефти, которое принадлежит ООО «ЛУКОЙЛ-Пермь». В административном отношении Речное месторождение расположено на юге Пермского края, осложняя северную часть Башкирского свода. По данным 3D-сейсморазведки на данном месторождении единственно возможным нефтегазоносным комплексом является визейский (C1v), амплитуда структуры которого составляет 19 м. Предварительная оценка ресурсов нефти, проведенная ООО «ЛУКОЙЛ-Пермь», составила 215 тыс.т.

Интервалы и распределения подсчетных параметров, возможные для данной территории, были установлены по результатам анализа 23 месторождений-аналогов, расположенных в единой структурно-фациальной зоне и зоне нефтегазонакопления. Анализ и моделирование проводилось с использованием программного пакета Statistica 6. В пределах месторождений было оценено 106 продуктивных пластов, слагающих 48 поднятий. Площадь нефтеносности установлена по данным сейсморазведки.

Представив значения основных параметров месторождений-аналогов, которые используются при подсчете запасов, в виде гистограмм (рис. 2), можно дать прогнозную оценку типа их распределения и основных уровней оценки $(P 90$, $P$ mean, $P 10)$. Таким образом, можно судить о вероятности получения данного значения. Например, для Речного месторождения с 90\%-й уверенностью будет достигнута эффективная нефтенасыщенная толщина, равная 1,83 м.

Тип распределения, как наиболее приемлемый, выбирается исходя из проверки, согласно критерию Колмогорова-Смирнова (табл. 1) [12, 13]. В табл. 1 выделены минимальные значения критерия Колмогорова-Смирнова. Анализ показывает, что для параметров эффективной нефтенасыщенной толщины и пересчетного коэффициента соответствует Beta-распределение, для коэффициентов пористости и нефтенасыщенности - Min Extreme, для КИН - Max Extreme и для плотности нефти - Gamma-распределение.

Выбранному и проверенному типу распределения соответствуют основные параметры, представленные в табл. 2. 


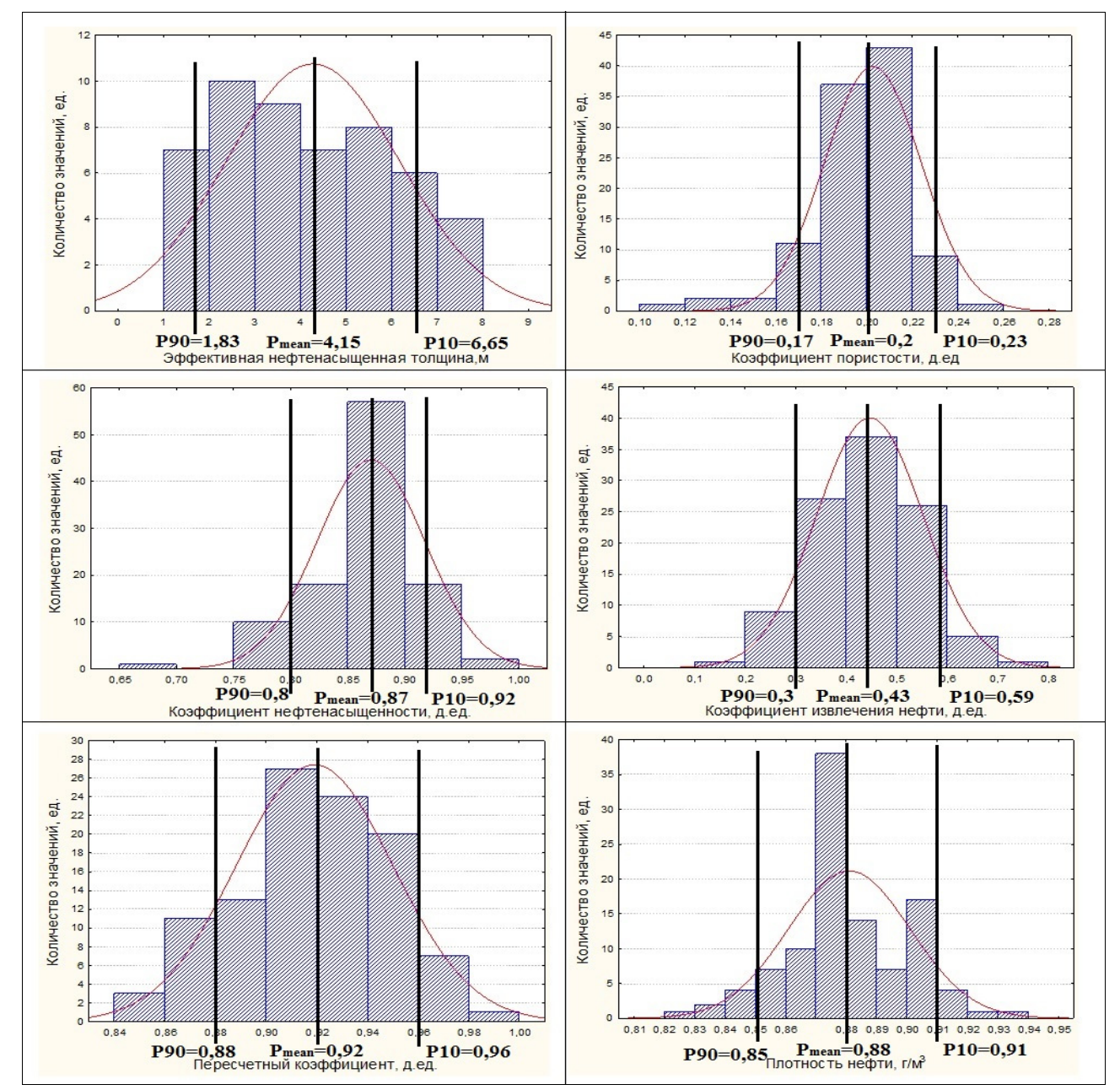

Рис. 2. Гистограмма распределения подсчетных параметров Речного месторождения

Таблица 1

Обоснование типов распределений подсчетных параметров

Речного месторождения по критерию Колмогорова-Смирнова

\begin{tabular}{|l|c|c|c|c|c|c|}
\hline $\begin{array}{c}\text { Тип } \\
\text { распреде- } \\
\text { ления }\end{array}$ & $\begin{array}{c}\text { Эффективная } \\
\text { нефтенасыщен- } \\
\text { ная толщина }\end{array}$ & $\begin{array}{c}\text { Коэффициент } \\
\text { пористости }\end{array}$ & $\begin{array}{c}\text { Коэффициент } \\
\text { нефтенасы- } \\
\text { щенности }\end{array}$ & КИН & $\begin{array}{c}\text { Пересчетный } \\
\text { коэффициент }\end{array}$ & $\begin{array}{c}\text { Плотность } \\
\text { нефти }\end{array}$ \\
\hline Beta & $\mathbf{0 , 0 6 8 4}$ & 0,177 & 0,1282 & 0,1161 & $\mathbf{0 , 0 9 0 4}$ & 0,0975 \\
\hline Gamma & 0,0751 & 0,1818 & 0,1331 & 0,1249 & 0,1162 & $\mathbf{0 , 0 9 3 4}$ \\
\hline Lognormal & 0,0835 & 0,2005 & 0,1539 & 0,1242 & 0,1164 & 0,0965 \\
\hline MaxExtreme & 0,1069 & 0,2093 & 0,1733 & $\mathbf{0 , 0 8 9}$ & 0,0942 & 0,1473 \\
\hline Normal & 0,1093 & 0,1771 & 0,1282 & 0,1242 & 0,1193 & 0,0975 \\
\hline MinExtreme & 0,1923 & $\mathbf{0 , 1 4 7 9}$ & $\mathbf{0 , 0 9 6 4}$ & 0,1057 & 0,149 & 0,1464 \\
\hline Exponential & 0,2913 & 0,5216 & 0,5733 & 0,4257 & 0,6048 & 0,6099 \\
\hline Uniform & 0,3674 & 0,3987 & 0,3935 & 0,1929 & 0,1426 & 0,2064 \\
\hline
\end{tabular}


Таблица 2

Параметры типа распределения подсчетных параметров Речного месторождения

\begin{tabular}{|c|c|c|c|c|c|c|}
\hline \multirow{2}{*}{$\begin{array}{c}\text { Тип } \\
\text { распре- } \\
\text { деления }\end{array}$} & $\begin{array}{c}\text { Эффективная } \\
\text { нефтенасыщен- } \\
\text { ная толщина }\end{array}$ & $\begin{array}{c}\text { Коэффи- } \\
\text { циент } \\
\text { пористости } \\
\end{array}$ & $\begin{array}{c}\text { Коэффициент } \\
\text { нефтенасы- } \\
\text { щенности } \\
\end{array}$ & КИН & $\begin{array}{c}\text { Пересчет- } \\
\text { ный коэф- } \\
\text { фициент } \\
\end{array}$ & $\begin{array}{c}\text { Плотность } \\
\text { нефти }\end{array}$ \\
\hline & Beta & $\begin{array}{c}\text { Min- } \\
\text { Extreme }\end{array}$ & $\begin{array}{c}\text { Min- } \\
\text { Extreme }\end{array}$ & $\begin{array}{c}\text { Max- } \\
\text { Extreme }\end{array}$ & Beta & Gamma \\
\hline Minimum & 1,1 & 0,117 & 0,68 & 0,15 & 0,85 & 0,829 \\
\hline Maximum & 8 & 0,25 & 0,96 & 0,718 & 0,99 & 0.937 \\
\hline Alpha & 1,123 & - & - & - & 1,899 & - \\
\hline Beta & 1,564 & - & - & - & 1,983 & - \\
\hline Likeliest & - & 0,21 & 0,89 & 0,39 & - & - \\
\hline Scale & - & 0,02 & 0,04 & 0,1 & - & - \\
\hline Location & - & - & - & - & - & 0,25 \\
\hline Scale & - & - & - & - & - & 0 \\
\hline Shape & - & - & - & - & - & 999 \\
\hline
\end{tabular}

Используя данные распределений, представленные в табл. 2, и проведя 10000 итераций определения случайных величин параметра, получаем скорректированные данные. Сопоставив распределения по всем подсчетным параметрам, входящим в формулу подсчета запасов, получаем график, соответствующий распределению извлекаемых запасов нефти, который представлен на рис. 3.

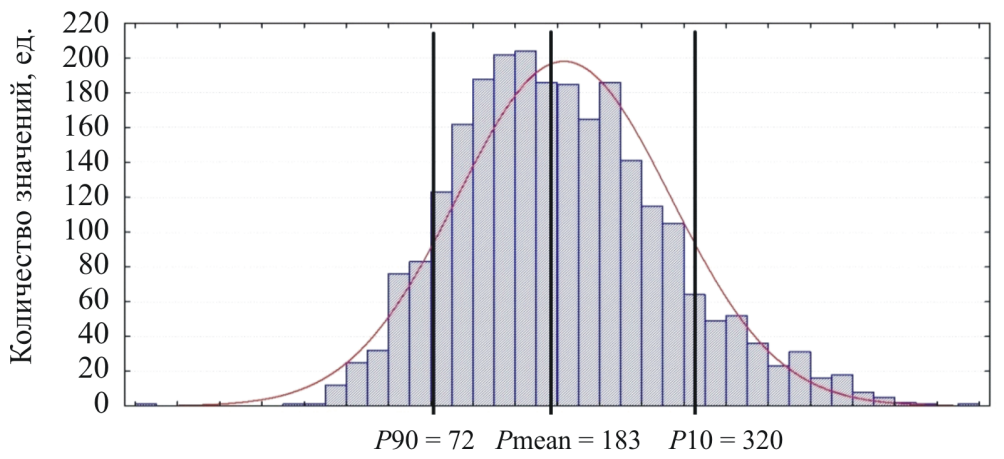

Извлекаемые запасы нефти, тыс. т

Рис. 3. Гистограмма распределения извлекаемых запасов нефти по C1v НГК (визейскому нефтегазоносному комплексу)

Речного месторождения

Анализ показал, что наиболее достоверным значением является среднее значение диапазона возможных объемов ресурсов (Pmean) - 183 тыс.т. Таким образом, можно сделать вывод, что предварительная оценка ресурсов нефти 
Речного месторождения, проведенная ООО «ЛУКОЙЛ-Пермь», завышена на 36 тыс. т.

В табл. 3 представлены итоги расчета экономической эффективности инвестиций в проект разработки Речного месторождения компанией ООО «ЛУКОЙЛ-Пермь», с учетом вероятностной оценки прогнозных ресурсов нефти и без ее проведения.

Таблица 3

Сравнение показателей эффективности проекта поисково-оценочных работ на Речном месторождении

\begin{tabular}{|l|c|c|c|}
\hline \multicolumn{1}{|c|}{ Показатель } & $\begin{array}{c}\text { Величина без } \\
\text { применения } \\
\text { вероятностной } \\
\text { оценки }\end{array}$ & $\begin{array}{c}\text { Величина } \\
\text { с применением } \\
\text { вероятностной } \\
\text { оценки }\end{array}$ & $\begin{array}{c}\text { Отклонение } \\
\text { показателя }\end{array}$ \\
\hline Запасы, тыс. т & 215 & 183 & -32 \\
\hline Затраты, тыс. руб. & 904816,5 & 771981,3 & $-132835,2$ \\
\hline Инвестиции, тыс. руб. & 136500,00 & 136500,00 & 0 \\
\hline $\begin{array}{l}\text { Чистый дисконтированный доход, } \\
\text { тыс. руб. }\end{array}$ & 274593,89 & 213992,38 & $-60601,51$ \\
\hline Дисконтированный срок окупаемости, лет & 1,9 & 2,1 & $+0,2$ \\
\hline Индекс рентабельности, о.е. & 2,0 & 1,57 & $-0,43$ \\
\hline Внутренняя норма рентабельности, \% & 98,0 & 92,4 & $-5,6$ \\
\hline
\end{tabular}

Анализ данных табл. 3 показывает, что применение методики оценки уровня потенциальных запасов углеводородов на Речном месторождении на основе стохастического моделирования позволит снизить затраты ООО «ЛУКОЙЛ-Пермь» на 132 835,2 тыс. руб. и повысить уровень доходов проекта на 60 коп. с каждого вложенного рубля в проект.

Прогнозная оценка ресурсов позволяет сделать корректный вывод о целесообразности реализации инвестиционного проекта по добыче углеводородов и наиболее достоверно рассчитать предполагаемый экономический эффект для предприятия. На основе полученных данных об объеме полезных ископаемых наиболее полно и грамотно можно выбрать модель обустройства месторождения и оборудования, тем самым оптимизировать затраты [14] и перераспределить денежные средства в другие прибыльные проекты.

\section{Список литературы}

1. Афтахова У.В. Методический инструментарий минимизации социальных рисков промышленного развития // Проблемы современной экономики. 2015. - № 2. - С. 228-231.

2. Поляков А.А., Мурзин Ш.М. Международный опыт анализа геологических рисков [Электронный ресурс] // Нефтегазовая геология. Теория и 
практика. - 2012. - Т. 7, № 4. - URL: http://www.ngtp.ru/rub/3/60_2012.pdf (дата обращения: 15.02 .2017$)$.

3. Исаева Н.С. Оценка эффективности управления ресурсами и запасами углеводородов нефтегазовыми компаниями: дис. ... канд. экон. наук / Нац. исслед. ун-т им. Н.М. Губкина. - М., 2016. - 155 с.

4. Хафизов Ф.З. Анализ запасов нефти. - 2-е изд., доп. - Тюмень: Изд-во ТюмГНГУ. - 2015. - 360 с.

5. Методические ошибки при подсчете запасов: вид и величина мощности (на примере Борисовского месторождения Припятского прогиба) / Е.Г. Паремский, А.С. Грудинин, В.Г. Седач, Ю.А. Гапонова // Нефтяник Полесья. - Речица, 2015. - Вып. № 2(28). - С. 56-65.

6. Фокин А. Риски и неопределенности в геологоразведочном процессе // Новатор. - 2011. - № 43. - С. 8-12.

7. Шаклеин С.В., Рогова Т.Б. Оценка риска пользования недрами: учеб. пособие / Кузб. гос. техн. ун-т. - Кемерово, 2009. - 120 с.

8. Фалин Г.И. Метод Монте-Карло в теории риска. - URL: http:// mech.math.msu.su/ falin/files/Фалин(2016)Метод_Монте-Карло_в_теории_риска.pdf (дата обращения: 15.02.2017).

9. Волкова М.С. Стохастическое моделирование на основе многоточечной статистики с применением сейсмических атрибутов в качестве обучающих образцов // Геофизика. - 2015. - № 6. - С. 68-73.

10. Галкин В.И., Растегаев А.В., Козлова И.А. Сравнение запасов нефти по российской и международной классификациям. - Пермь: Изд-во Перм. гос. техн. ун-та, 2007. - 244 с.

11. Жуланов Е.Е. Экономика нефтяной и газовой промышленности: учеб. пособие. - Пермь: Изд-во Перм. гос. техн. ун-та, 2009. - 116 с.

12. Мицель А.А. Прикладная математическая статистика. Практические работы. - Томск: ТУСУР, 2015. - 81 с.

13. Орлов А.И. Непараметрические критерии согласия Колмогорова, Смирнова, омега-квадрат и ошибки при их применении [Электронный ресурс] // Научный журнал КубГАУ. - 2014. - № 97 (03). - URL: http:// ej.kubagro.ru/2014/03/pdf/47.pdf (дата обращения: 15.02.2017).

14. Жуланов Е.Е. Формирование механизма минимизации затрат региональных предприятий на производственные ресурсы с учетом технологических ограничений // Современная экономика: проблемы и решения. - 2014. № 1 (49). - С. 78-88.

\section{References}

1. Aftakhova U.V. Metodicheskii instrumentarii minimizatsii sotsial'nykh riskov promyshlennogo razvitiia [Methodological tools for minimizing social 
risks of industrial development]. Problemy sovremennoi ekonomiki, 2015, no. 2, pp. 228-231.

2. Poliakov A.A., Murzin Sh.M. Mezhdunarodnyi opyt analiza geologicheskikh riskov [International experience in geological risks analysis]. Neftegazovaia geologiia. Teoriia i praktika, 2012, no. 4, vol. 7. Available at: http://www.ngtp.ru/ rub/3/60_2012.pdf (accessed 15 February 2017).

3. Isaeva N.S. Otsenka effektivnosti upravleniia resursami i zapasami uglevodorodov neftegazovymi kompaniiami [Estimation of hydrocarbon resources effectiveness and hydrocarbon reserves management by oil and gas companies]. Ph. D. thesis. Moscow, 2016, 155 p.

4. Khafizov F.Z. Analiz zapasov nefti [Oil reserves analysis]. 2nd ed., revised. Tyumen, Tyumen State Oil-and-Gas University, 2015, 360 p.

5. Metodicheskie oshibki pri podschete zapasov: vid i velichina moshchnosti (na primere Borisovskogo mestorozhdeniia Pripiatskogo progiba) [Methodological errors in reserves calculation: Power type and magnitude (the case study of Borisovskoye deposit of the Pripyat Trough)]. Neftianik Poles'ia, 2015, no. 2(28), p. 56-65.

6. Fokin A. Riski i neopredelennosti v geologorazvedochnom protsesse [Risks and uncertainties in geological exploration process]. Novator, 2011, no. 43, pp. 8-12.

7. Shaklein S.V., Rogova T.B. Otsenka riska pol'zovaniia nedrami [Risks assessment of subsoil use]. Kemerovo, Kuzbass State Technical University, 2009, 120 p.

8. Falin G.I. Metod Monte-Karlo v teorii riska [Monte Carlo method in risk theory]. Available at: http://mech.math.msu.su/ falin/files/Фалин(2016)Метод_МонтеКарло_в_теории_риска.pdf (accessed 15 February 2017).

9. Volkova M.S. Stokhasticheskoe modelirovanie na osnove mnogotochechnoi statistiki s primeneniem seismicheskikh atributov $\mathrm{v}$ kachestve obuchaiushchikh obraztsov [Stochastic modeling based on multipoint statistics with the use of seismic attributes as training samples]. Geofizika, 2015, no. 6, pp. 68-73.

10. Galkin V.I., Rastegaev A.V., Kozlova I.A. Sravnenie zapasov nefti po rossiiskoi i mezhdunarodnoi klassifikatsiiam [Oil reserves comparison in the Russian and international classifications]. Perm, PSTU Publ., 2007, 244 p.

11. Zhulanov E.E. Ekonomika neftianoi i gazovoi promyshlennosti [Economics of oil and gas industry]. Perm, Perm State Technical University Publ., 2009, $116 \mathrm{p}$.

12. Mitsel' A.A. Prikladnaia matematicheskaia statistika. Prakticheskie raboty [Applied mathematical statistics. Practical works]. Tomsk, TUSUR University, 2015, $81 \mathrm{p}$.

13. Orlov A.I. Neparametricheskie kriterii soglasiia Kolmogorova, Smirnova, omega-kvadrat i oshibki pri ikh primenenii [Non-parametric criteria of Kolmogorov and Smirnov's agreement, omega-square and errors in their application]. Nauchnyi zhurnal KubGAU, 2014, no. 97, vol. 3. Available at: http://ej.kubagro.ru/2014/03/pdf/47.pdf (accessed 15 February 2017). 
14. Zhulanov E.E. Formirovanie mekhanizma minimizatsii zatrat regional'nykh predpriiatii na proizvodstvennye resursy $\mathrm{s}$ uchetom tekhnologicheskikh ogranichenii [Formation of a mechanism for minimizing regional enterprises' costs for resource production, taking technological constraints into account]. Sovremennaia ekonomika: problemy $i$ resheniia, 2014, no. 1 , vol. 49, pp. 78-88.

Оригинальность $89 \%$

Получено 13.03.2017 Принято 09.04.2017 Опубликовано 30.09.2017

\author{
U.V. Aftakhova, N.Yu. Starkova
}

\title{
DEVELOPMENT OF METHODOLOGY FOR POTENTIAL HYDROCARBON RESERVES LEVEL ASSESSMENT AT THE OILFIELD ON THE BASIS OF STOCHASTIC MODELING
}

\begin{abstract}
The article justifies the need for the assessment of the level of potential hydrocarbon reserves at an oilfield. The analysis of specialized literature reveals that the decision for investing into a field development project is based on the indicator of oil inferred resource level. According to the authors' point of view, the problem of inaccurate reserves assessment is becoming relevant today, as such inaccuracy in the assessment of hydrocarbon crude volume may lead to the insufficient economic impact in field development. The authors suggest stochastic modeling based on Monte Carlo method as the most suitable approach to potential hydrocarbon reserves level assessment under risk conditions. The application of this mathematical tool will allow a more accurate calculation of oil field volumetric parameters. The following methodology has been tested at Rechnoe oilfield owned by $\mathrm{OOO}$ Lukoil-Perm. The company estimates that the field's oil-bearing capacity comprises 215 kilotons. The calculations based on the above-mentioned methodology indicate excessive amount of estimated hydrocarbon crude volumes, which is sure to lead to the reduction in the effectiveness of field development. The article presents the cost-effectiveness analysis of the investments in Rechnoe oilfield. The comparison of the project performance indicators with and without the authors' methodology application proved that a more detailed potential hydrocarbon reserves level assessment at Rechnoe oilfield can improve the project's profitability.

Keywords: oil and gas companies, confidence level of hydrocarbon reserves assessment, oilbearing capacity assessment, Monte Carlo method, economic effect.
\end{abstract}

Ulyana V. Aftakhova - Senior Lecturer, Dept. of Economics and Industrial Management, Perm National Research Polytechnic University, e-mail: ulianaaft@yandex.ru.

Nelli Yu. Starkova - Graduate Student, Dept. of Economics and Industrial Management, Perm National Research Polytechnic University, e-mail: nelly9418@mail.ru.

Received 13.03.2017 Accepted 09.04.2017 Published 30.09.2017 